\title{
Emission of Carbonaceous Species from Biomass Burning in the Traditional Rural Cooking Stove in Bangladesh
}

\author{
Morshad Ahmed1', M. Das',2, T. Afser ${ }^{1}$, M. Rokonujjaman'1, T. Akther1 ${ }^{1}$, A. Salam ${ }^{1 *}$ \\ ${ }^{1}$ Department of Chemistry, University of Dhaka, Dhaka, Bangladesh \\ ${ }^{2}$ Department of Chemistry, Kyungpook National University, Daegu, South Korea \\ Email:*asalam@gmail.com
}

How to cite this paper: Ahmed, M., Das, M., Afser, T., Rokonujjaman, M., Akther, T. and Salam, A. (2018) Emission of Carbonaceous Species from Biomass Burning in the Traditional Rural Cooking Stove in Bangladesh. Open Journal of Air Pollution, 7, 287-297.

https://doi.org/10.4236/ojap.2018.74014

Received: August 23, 2018

Accepted: October 8, 2018

Published: October 11, 2018

Copyright $\odot 2018$ by authors and Scientific Research Publishing Inc. This work is licensed under the Creative Commons Attribution International License (CC BY 4.0).

http://creativecommons.org/licenses/by/4.0/

\begin{abstract}
Characterization of carbonaceous species from the particulate matters (PM) after combustion of seven commonly used biomass species, albizia tree (Albizia julibrissin), dry leaves (mahogany tree), jackfruit tree (Artocarpus heterophyllus), rain tree (Samanea saman), mahogany tree (Swietenia mahogany), cow dung and mango tree (Mangifer aindica) was done. PM samples were collected on quartz fiber filters emitted from biomass burning in a typical rural cooking stove. PM loaded filters were characterized with scanning electron microscope (SEM) for surface morphology, fourier transform infrared (FTIR) to determine the functional group of organic compounds. Black carbon (BC) and brown carbon $(\mathrm{BrC})$ concentrations were determined with Aethalometer. A TOC analyzer was used to determine the total organic carbon (TOC) present in the biomass samples. The surface morphology was almost similar for all biomass burning PM samples. The average concentrations of $\mathrm{BC}$ and $\mathrm{BrC}$ were $5.85 \pm 4.40$ and $13.0 \pm 8.80 \mu \mathrm{g} \cdot \mathrm{m}^{-3}$, respectively. The emission factors of $\mathrm{BC}$ and $\mathrm{BrC}$ were $1.08 \pm 0.89$ and $2.35 \pm 1.67 \mathrm{mg} \cdot \mathrm{g}^{-1}$, respectively. Concentration of $\mathrm{BC}$ was the highest in dry leaves and the lowest in mango tree. The emission factors of the determined biomass followed the sequence-dry leaves of mahogany $>$ albizia tree $>$ jackfruit tree $>$ rain tree $>$ cow dung $>$ mahogany tree $>$ mango tree. PM from mango tree had lower emissions compared to the other biomass species used in this study.
\end{abstract}

\section{Keywords}

Biomass Burning, Particulate Matter, Black Carbon, Brown Carbon, Total Organic Carbon

\section{Introduction}

Biomass burning is considered as the significant source of air pollution, which 
has serious impact both on public health and climate. Solid biomass burning releases large amount of pollutants like particulate matter (PM), black carbon (BC), Organic carbon (OC), carbon monoxide (CO), formaldehyde etc. [1]. These pollutants are causing respiratory infections, pulmonary diseases, asthma and diseases of the eye. PM 2.5 can enter deep into the lung and responsible for more than 3.1 million deaths in 2010 [2] [3]. Moreover, pollutants from the household biomass burning can result in more than 1.6 million deaths per annum [4]. In addition to human health, biomass burning has adverse effects on the climate. It is considered as the most significant source of BC emissions in the atmosphere [5] especially South East Asia, which is very efficient in absorbing solar radiation [6]. In recent studies, light absorbing organic aerosol, which is known as brown carbon ( $\mathrm{BrC}$ ) [7] [8] [9] is increasingly included in climate models that can also absorb solar radiation efficiently at specific wavelengths [10] to know the carbonaceous aerosol role in global climate [11]-[16]. Previously we have reported the emissions of trace metals in black solid materials from biomass burning [17]. Whereas, no information is available for black carbon $(\mathrm{BC})$ and brown carbon ( $\mathrm{BrC}$ ) emissions from biomass burning.

Bangladesh is a rapidly growing Southeast Asian country but about $80 \%$ people of the country are still living in the rural areas. Most of the cooking in rural areas of Bangladesh is done in indoor environments with very little ventilation. Almost $70 \%$ of them are using various biomass species, including rice husk, straw, cow dung, jute stick, bagasse, bamboo, dry leaves, and woods as main fuels for cooking foods [18]. Biomass burning is producing huge amount of PM, toxic gaseous pollutants $\left(\mathrm{NO}_{\mathrm{X}}, \mathrm{SO}_{\mathrm{X}}, \mathrm{CO}_{2}, \mathrm{CO}, \mathrm{VOC}\right.$ etc.) and heavy metals $(\mathrm{Pb}$, $\mathrm{Cu}, \mathrm{Co}$ and $\mathrm{Zn}$ etc.) [19]. Production of these pollutants depends significantly on the position of kitchen, types of fuel use, and also ventilation on indoor air quality [20]. However, very limited information is available for the characterization of biomass burning emission in Bangladesh.

Therefore, we are focusing on the $\mathrm{BC}, \mathrm{BrC}$ and $\mathrm{TOC}$ emissions of seven commonly used biomasses in the rural cooking stove in Bangladesh. PM was collected on quartz filter and analyzed for surface morphology with scanning electron microscope (SEM), functional group of various organic compounds with fourier transform infra-red (FTIR) spectroscopy, concentrations and emission factors for $\mathrm{BC}$ and $\mathrm{BrC}$ with an aethalometer and total organic carbon (TOC) concentration with an TOC analyzer.

\section{Methods and Experimental}

\subsection{Physical Characteristics of the Biomass Samples}

Seven different biomass samples, e.g., albizia tree (Albizia julibrissin), dry leaves (mahogany tree), jackfruit tree (Artocarpus heterophyllus), rain tree (Samanea saman), mahogany tree (Swietenia mahogany), cow dung and mango tree (Mangifer aindica) were selected which are widely used for cooking purposes in rural and sub-rural areas in Bangladesh. Among all mahogany and jackfruit trees were 
hard wood; mango, albizia and rain trees were moderately hard wood, whereas dry leaves and cow dung were very light species. All the species were collected from Barisal district (southern part of Bangladesh) during the winter season (December, 2014-February, 2015) and transported to the Department of Chemistry, University of Dhaka. The species were cut into small pieces with a length of 4 inches and dried for burning in the cooking stove.

\subsection{Description of Cooking Stove}

Deposition of PM by biomass burning is dependent on both types of biomass and cooking stoves [20]. Almost all the cooking stoves are made of mud (local name is "Chula") with one or multi-channel in rural and sub-rural areas in Bangladesh. A two channel, mobile cooking stove was made with mud in the Atmospheric and Environmental Research Laboratory, Department of Chemistry, University of Dhaka where the experiments were carried out.

\subsection{Particulate Matter (PM) Sample Collection}

PM samples were collected from the combustion of seven biomass species. Before sampling each quartz filter (Gelman, membrane filters, $47 \mathrm{~mm}$ diameter) was heated at $800^{\circ} \mathrm{C}$ for 4 hours to remove all impurities. The one stage inline 9631, NILU filter holder (diameter $90 \mathrm{~mm}$, length $70 \mathrm{~mm}$ ) filled with quartz filters were placed about $31 \mathrm{~cm}$ on top of the cooking stove. About $50.0 \mathrm{~g}$ of each biomass species was fed into the cooking stove for burning. Deposited PM weight was calculated from the differences between PM loaded and unloaded filters. The volume of air was recorded from the difference of the initial and final Gas meter reading. The PM loaded filters were kept in a petri-disk and preserved in a desiccator to prevent moister at controlled temperature and humidity.

\subsection{Analytical Method}

\subsubsection{Scanning Electron Microscope (SEM)}

A scanning electron microscope (SEM), (model "JEOL", SN-JSM-6490LA, Japan) was used to characterize the surface morphology of the PM samples. Magnification range of the SEM images was $\times 1000-\times 50,000$. The expected particle size of the PM in quartz filters was $1 \mu \mathrm{m}-100 \mu \mathrm{m}$.

\subsubsection{FTIR Analysis}

A fourier transform infrared spectrometer (model "IR Prestige 21", SN-A21004902879LP, Japan) was used to study the functional group of the PM particles. A very thin layer of PM was taken from the quartz filter with a spoon and mixed properly with potassium bromide $(\mathrm{KBr})$ finely to remove scattering effects from large crystals. A mechanical press is used to press the resultant powder to a translucent pellet through which the beam of the spectrometer can pass. IR spectroscopy is often used to identify structures because functional groups give rise to characteristic bands, both in terms of intensity and position (frequency). 


\subsubsection{Aethalometer Data Analysis}

The soot $\operatorname{scan}^{\text {tw }}$ model OT21 transmissometer (Magee scientific transmissometer OT21; USA) bench top analyzer was used to measure both $\mathrm{BC}$ and $\mathrm{BrC}$ from different biomass burning emissions. This aethalometer contains a two wavelength light source: 1) $880 \mathrm{~nm}$ providing the quantitative measurement of $\mathrm{BC}$ (near IR range), and 2) $370 \mathrm{~nm}$ for measurement of $\mathrm{BrC}$ (UV visible range). The light was passed through the PM loaded filters that decrease the transmission of light, and the decreasing of transmission leads to the increasing attenuation [21]. Transmission of light through the sample-laden filter is measured and the attenuation (ATN) coefficient is calculated from the rate of attenuation change with time [22].

\section{1) Attenuation Measurement}

$\mathrm{BC}$ mass concentrations were estimated by an aethalometer from the rate of change of light transmission through a filter [23]. As the transmission decreases attenuation increases. Attenuation factor for both $\mathrm{BC}$ and $\mathrm{BrC}$ were determined in PM loaded filters by using the following equations [24]:

$$
A T N=100 \times \ln (\text { blank transmission/sample transmission })
$$

where $A T N$ is the attenuation factor. $A T N_{1}$ is the attenuation factor before heating of the PM loaded filters and $A T N_{2}$ is the attenuation factor after heating the sampled filters at $340^{\circ} \mathrm{C}$ for 3 hours for both blank and sample filters at both wavelengths in aethalometer (IR reading at $880 \mathrm{~nm}$ and UV reading at $370 \mathrm{~nm}$ ).

\section{2) $\mathrm{BC}$ and BrC Emission Measurement}

The density of $\mathrm{BC}$ and $\mathrm{BrC}$ were calculated by using $A T N$ value at $880 \mathrm{~nm}$ and $370 \mathrm{~nm}$, respectively with the following equation:

$$
\delta=\left(A T N_{1}-A T N_{2}\right) / \sigma_{A T N}
$$

where $\delta$ is the carbon density in $\mu \mathrm{g} \cdot \mathrm{cm}^{-2}$ and $\sigma_{A T N}$ is the specific attenuation co-efficient, which is $16.6 \mathrm{~cm}^{2} \cdot \mu \mathrm{g}^{-1}$. The concentration of $\mathrm{BC}$ and $\mathrm{BrC}$ were calculated from the density of $\mathrm{BC}$ and $\mathrm{BrC}$ by using the following equation:

$$
C_{d}=(\delta \times A) / V_{m s}
$$

where $C_{d}$ is the measured carbon concentration $\left(\mu \mathrm{g} \cdot \mathrm{m}^{-3}\right), A$ is the collection area of the filter $\left(14.5 \mathrm{~cm}^{2}\right)$ and $V_{m s}=$ volume of air during sampling from the dry gas meter.

\section{3) Emission Factor Estimation of $\mathrm{BC}$ and $\mathrm{BrC}$}

Residential biomass burning emission factors is very important as they provide a measure of the amount of pollutants emitted to the atmosphere per mass of fuel combusted. The emission of $\mathrm{BC}$ and $\mathrm{BrC}$ were calculated from the concentration of $\mathrm{BC}$ and $\mathrm{BrC}$ by using the following equation:

$$
E=(F c \times C d \times 100 \%) / \% \mathrm{CO}_{2}
$$

where $E$ is black carbon emission $\left(\mu \mathrm{g} \cdot \mathrm{j}^{-1}\right)$ and $F c$ is Carbon based $F$ factor $\left(\mathrm{m}^{3} \cdot \mathrm{j}^{-1}\right)$ which is $4.84 \times 10^{-6} \mathrm{~m}^{3} \cdot j^{-1}$. The carbon dioxide percentage of the sampling area was 0.031 . The emission factors for seven biomasses were calculated using the 
following equation:

$$
E F=(E \times G C V) / 1000
$$

$E F$ is carbon emission factor $\left(\mathrm{mg} \cdot \mathrm{g}^{-1}\right), E$ is black carbon emission $\left(\mu \mathrm{g} \cdot \mathrm{j}^{-1}\right)$ and $G C V=$ gross calorific value of fuel.

\subsubsection{Total Organic Carbon (TOC) Determination}

A TOC analyzer (model "TOC-V CPN"; SN-H51304500919AE, Japan) was used to determine the total organic carbon present in the PM after burning of each biomass species. The filter samples were dissolved in a $15 \mathrm{~mL}$ de-ionized water in reagent bottles. After that the reagent bottles containing samples were placed in a shaking bath for one hour and then sonicated in an ultrasonic bath for 30 minutes. Finally, all the solutions were carried for the determination of total organic carbon (TOC) concentration.

\section{Results and Discussion}

\subsection{Overview of the Results}

This study involves emission of carbonaceous species from seven biomasses in a typical rural cooking stove made of mud. Albizia tree, dry leaves of mahogany, jackfruit tree, rain tree, mahogany, cow dung and mango tree were used as biomasses. Particulate matters (PM) were collected on quartz filters with an SPM sampler (TUV, Austria) on about $31 \mathrm{~cm}$ top of the cooking stove. Surface morphology of the PM was studied with SEM and both coarse and fine particles were obtained for seven biomass species. Functional group of various organic compounds was analyzed with FTIR and they are quite similar to each other. The concentrations and emission factor for $\mathrm{BC}$ and $\mathrm{BrC}$ were analyzed using a two wavelength aethalometer after burning of each biomass separately in the cooking stove. $\mathrm{BrC}$ concentrations and emission factor was higher than $\mathrm{BC}$ for all biomass species. The highest amount of BC content found in the dry leaf of mahogany tree and the lowest amount of $\mathrm{BC}$ found in the mango tree. The highest amount of $\mathrm{BrC}$ content found in the albizia tree and lowest amount in the mango tree. TOC in PM was analyzed by TOC analyzer for individual biomass species. Among all biomasses albizia contains the highest amount of TOC, whereas mango shows the lowest.

\subsection{Surface Characterization with Scanning Electron Microscope (SEM)}

Scanning electron microscope (SEM) was used to characterize the surface morphology of the PM obtained from seven biomass species (albizia, dry leaves, jackfruit, rain, mahogany, cow dung and mango) after burning in the cooking stove. Two types of particle (coarse and fine) were obtained. Coarse particles (particles having diameter $>2.5 \mu \mathrm{m}$ ) were found for cow dung, dry leaves, mahogany and mango; whereas, fine particles were found (particles having diameter $<2.5 \mu \mathrm{m}$ ) for albizia, jackfruit and rain. Salam et al. reported that the smoke 
deposits surfaces may contain dust, sulfate, nitrate and also oxides of different metals dominating by carbonaceous species [25].

\subsection{Functional Group Identification with Fourier Transform Infrared (FTIR) Spectroscopy}

IR spectrum was taken of the PM of seven biomasses. Individual spectrum was obtained for the respective functional groups of various organic compounds for seven different biomass samples which have shown below (Table 1).

\subsection{Concentration of Black Carbon (BC) and Brown Carbon (BrC)}

\subsubsection{Black Carbon (BC)}

The $\mathrm{BC}$ and $\mathrm{BrC}$ concentrations were varied among the biomasses. The $\mathrm{BrC}$ concentrations were much higher than that of $\mathrm{BC}$ for all the biomasses (Figure 1). The average concentration of $\mathrm{BC}$ in all biomasses was $5.85 \mu \mathrm{g} \cdot \mathrm{m}^{-3}$. The $\mathrm{BC}$ concentration was highest in the dry leaves of mahogany tree and lowest in the mango tree. The $\mathrm{BC}$ concentration of seven biomass species was as follows-dry leaves $>$ albizia $>$ jackfruit $>$ rain $>$ cow dung $>$ mahogany $>$ mango. $B C$ concentration in the dry leaves of mahogany tree was almost 13 times higher than mango tree

\subsubsection{Brown Carbon (BrC)}

The average concentration of $\mathrm{BrC}$ was $13.0 \mu \mathrm{g} \cdot \mathrm{m}^{-3}$. The $\mathrm{BrC}$ concentration was highest in albizia tree and lowest in mango tree. The concentration of $\mathrm{BrC}$ in all biomasses followed the sequence-albizia $>$ dry leaves $>$ jackfruit $>$ rain tree $>$ cow dung $>$ mahogany tree $>$ mango tree (Figure 1). BrC concentration in albizia tree was almost 12 times higher than mango tree.

The $\mathrm{BrC}$ concentration compared to $\mathrm{BC}$ was 2.50 times higher in albizia tree, 1.50 times higher in dry leaves of mahogany tree, 2.75 times higher in Jackfruit tree, 2.50 times higher in rain tree, 2.0 times higher in cow dung, 3.00 times higher in mahogany tree and 2.75 times higher in mango tree.

\subsection{Emission Factor of Black Caron (BC) and Brown Carbon (BrC)}

\subsubsection{Black Carbon (BC)}

The average of emission factor for BC of all biomasses in this study was 1.09

$\mathrm{mg} \cdot \mathrm{g}^{-1}$. The emission factors for brown carbon were always higher than that of black carbon for seven biomasses. BC emission factor was highest in the dry leaves of mahogany tree and lowest in the mango tree. The order of $\mathrm{BC}$ emission factor was as follows-dry leaves $>$ albizia $>$ jackfruit $>$ rain $>$ cow dung $>$ mahogany $>$ mango (Figure 2).

\subsubsection{Black Carbon (BC)}

The average emission factor of $\mathrm{BrC}$ was $2.35 \mathrm{mg} \cdot \mathrm{g}^{-1}$. BrC emission factor was highest in albizia tree and lowest in mango tree. The $\mathrm{BrC}$ emission factor followed the sequence: albizia $>$ dry leaves $>$ jackfruit $>$ rain $>$ cow dung $>$ mahogany $>$ mango (Figure 2). 
Table 1. Characteristic functional group of the individual biomass burning emission with FTIR styles (Table caption is indispensable).
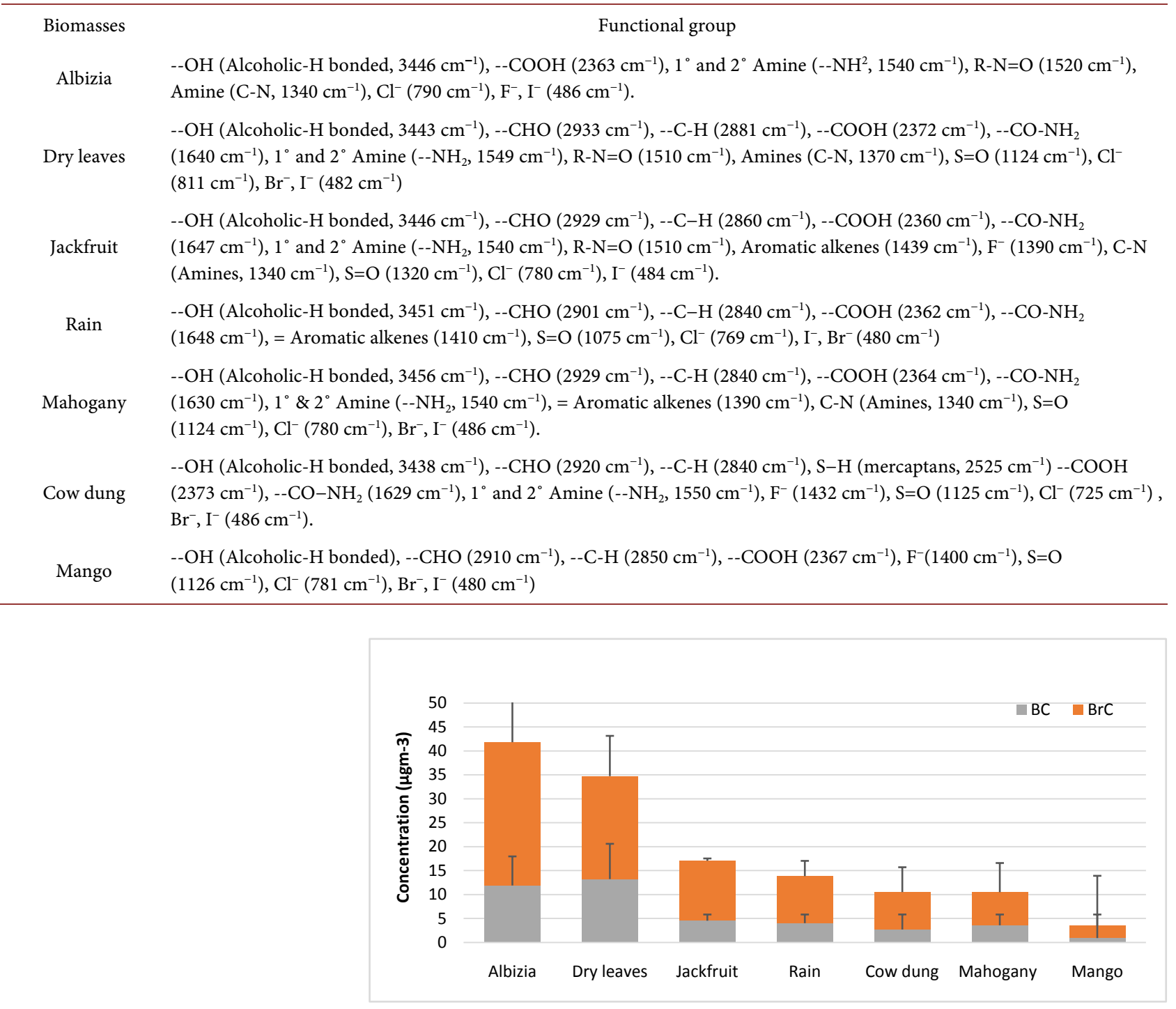

Figure 1. Comparison between $\mathrm{BC}$ and $\mathrm{BrC}$ concentrations in different biomass species.

The BrC emission factor compared to BC emission factor was 2.50 times greater in albizia tree, 1.65 times greater in dry leaves of mahogany tree, 2.75 times greater in jackfruit tree, 2.50 times greater in rain tree, 1.78 times greater in cow dung, 2.00 times greater in mahogany tree and 2.20 times greater in mango tree. The significance of the emission factor is that, if we multiply the emission factor of each biomass sample with a fixed amount of the respective biomass then we can find out the emission of carbon content ( $\mathrm{BC}$ and $\mathrm{BrC}$ ) for that amount of biomass.

\subsection{Total Organic Carbon (TOC) Concentration}

Total organic carbon (TOC) in albizia tree, dry leaves (mahogany tree), jackfruit tree, rain tree, cow dung, mahogany tree and mango tree was 5.07, 3.92, 3.51, 


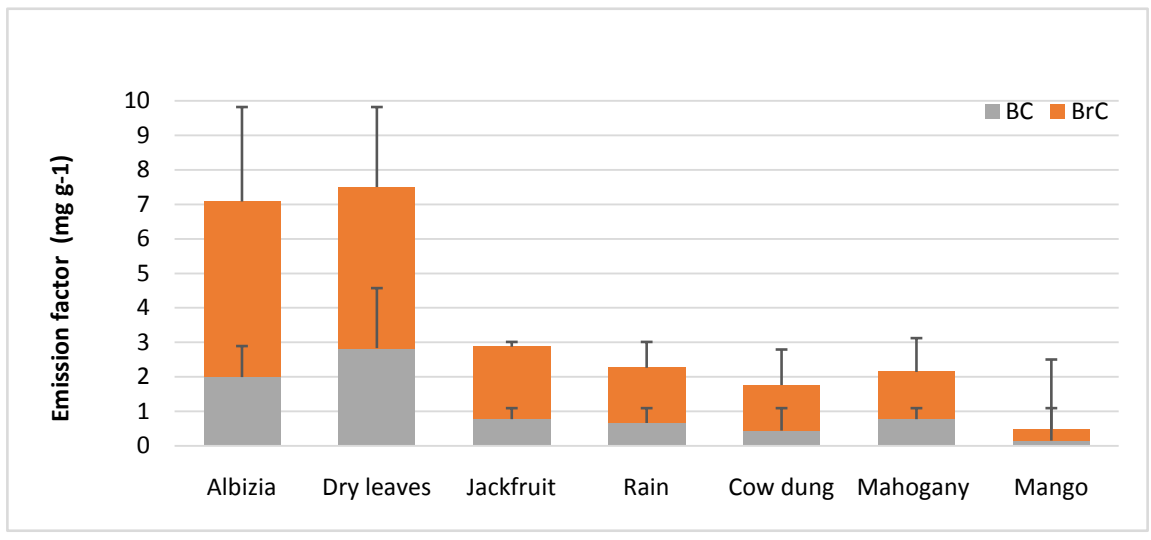

Figure 2. Comparison between $\mathrm{BC}$ and $\mathrm{BrC}$ emission factor in different biomass species.

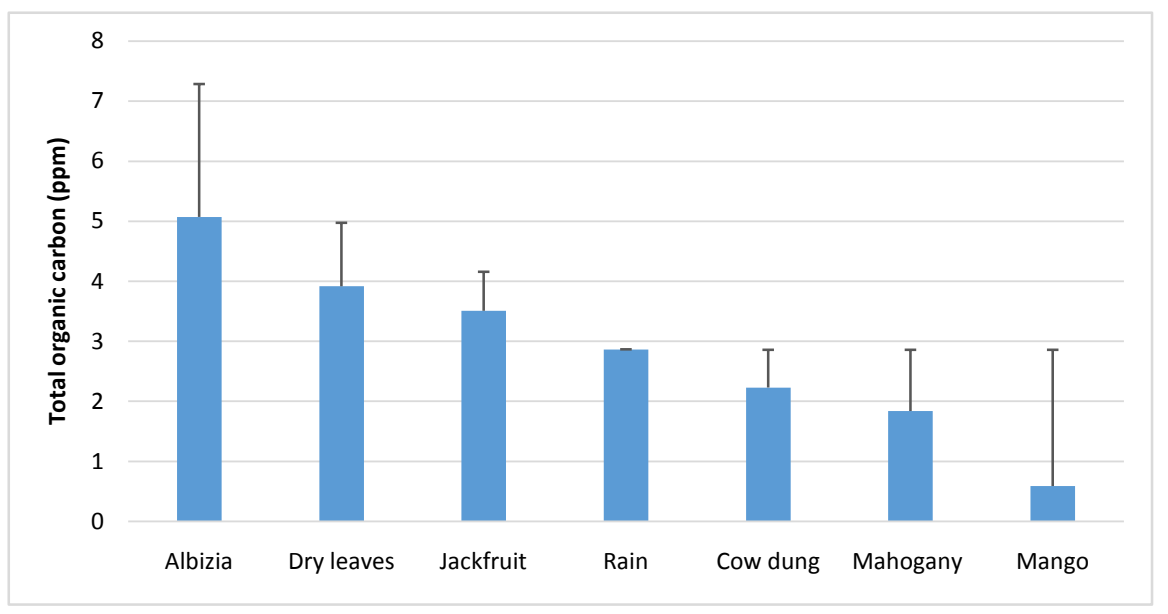

Figure 3. Total organic carbon (TOC) present in biomass sample.

$2.86,2.23,1.83$ and $0.58 \mathrm{ppm}$, respectively (Figure 3 ). The average TOC present in seven biomass samples was $2.86 \mathrm{ppm}$. The concentration of TOC was highest in albizia tree, whereas least in mango tree. In albizia tree the amount of TOC was 8.62 times higher than mango tree.

\section{Conclusions}

The study involves the carbonaceous species characterization of PM of seven biomasses (albizia tree, dry leaves of mahogany, jackfruit tree, rain tree, mahogany tree, cow dung and mango tree) after burning in a controlled cooking stove. The following conclusions are drawn from the present investigation:

- Coarse particles and fine particles were obtained from SEM. Particle sizes for cow dung, dry leaves, mahogany and mango were coarse in size; whereas, albizia, rain and jackfruit trees were fine in size.

- FTIR was used to analyze the functional group of various organic compounds. The functional groups of seven biomasses were almost similar.

- For all biomass species, concentration and emission factors for $\mathrm{BrC}$ were higher than BC. 
- Dry leaves contain the highest concentration of BC, whereas mango contains the lowest. On the other hand, albizia contains the maximum concentration of $\mathrm{BrC}$, whereas mango contains the minimum.

- TOC concentration was the highest for albizia and the lowest for mango.

- Mango tree emitted the lowest amount of BC, BrC and TOC that signifies that it has the least hazardous impact on the environment.

Therefore, we should be very much careful to select biomass species as an alternative to fossil fuel for cooking. For a better environmental aspect, we should use low $\mathrm{BC}$ and $\mathrm{BrC}$ containing biomasses like mango tree for cooking and other burning purposes.

\section{Acknowledgements}

Authors thank to the Department of States, USA and ARCADIS, USA for supporting us Soot Scanner. We acknowledge Mr. Chandra Nath for constructing cooking stove in the Chemistry laboratory, University of Dhaka, Bangladesh. Authors also like to express thanks to the CARS (Centre for Advanced Research in Sciences) for TOC analysis.

\section{Conflicts of Interest}

The authors declare no conflicts of interest regarding the publication of this paper.

\section{References}

[1] Roden, C.A., Bond, T., Conway, S., Pinel, A., MacCarty, N. and Still, D. (2009) Laboratory and Field Investigations of Particulate and Carbon Monoxide Emissions from Traditional and Improved Cookstoves. Atmospheric Environment, 43, 1170-1181. https://doi.org/10.1016/j.atmosenv.2008.05.041

[2] Xing, Y.F., Xu, Y., Shi, M. and Lian, Y. (2016) The Impact of PM2.5 on the Human Respiratory System. Journal of Thorasic Disease, 8, 69-74.

[3] Lim, S.S., Vos, T., Flaxman, A., Danaei, G., Shibuiya, K., Adair-Rohani, H. and AlMazroa, M. (2012) A Comparative Risk Assessment of Burden of Disease and Injury Attributable to 67 Risk Factors and Risk Factor Clusters in 21 Regions, 1990-2010: A Systematic Analysis for the Global Burden of Disease Study 2010. Lancet, 380 , 2224-2260. https://doi.org/10.1016/S0140-6736(12)61766-8

[4] WHO (2014) Household Air Pollution and Health. Fact Sheet N²92.

[5] Wang, Y., Hopke, P. and Utell, M. (2011) Urban-Scale Spatial-Temporal Variability of Black Carbon and Winter Residential Wood Combustion Particles. Aerosol \& Air Quality Research, 11, 473-481. https://doi.org/10.4209/aaqr.2011.01.0005

[6] Martins, V.J., Artaxo, P., Liousse, C., Reid, J., Hobbs, P. and Kaufman, Y. (1998) Effects of Black Carbon Content, Particle Size, and Mixing on Light Absorption by Aerosols from Biomass Burning in Brazil. Journal of Geophysical Research, 103 32041-32050. https://doi.org/10.1029/98JD02593

[7] Andreae, M.O. and Gelencsér, A. (2006) Black Carbon or Brown Carbon? The Nature of Light-Absorbing Carbonaceous Aerosols. Atmospheric Chemistry and Physics, 6, 3131-3148. https://doi.org/10.5194/acp-6-3131-2006

[8] Laskin, A., Laskin, J. and Nizkorodov, S. (2015) Chemistry of Atmospheric Brown 
Carbon. Chemical Reviews, 115, 4335-4382. https://doi.org/10.1021/cr5006167

[9] Moise, T., Flores, J. and Rudich, Y. (2015) Optical Properties of Secondary Organic Aerosols and Their Changes by Chemical Processes. Chemical Reviews, 115, 4400-4439. https://doi.org/10.1021/cr5005259

[10] Cherg, Y., He, K., Engling, G., Weber, R., Liu, J., Du, Z. and Dong, S. (2017) Brown and Black Carbon in Beijing Aerosol: Implications for the Effects of Brown Coating on Light Absorption by Black Carbon. Science of the Total Environment, 599-600, 1047-1055. https://doi.org/10.1016/j.scitotenv.2017.05.061

[11] Jacobson, M.Z. (2001) Global Direct Radiative Forcing Due to Multicomponent Anthropogenic and Natural Aerosols. Journal of Geophysical Research, 106, 1551-1568. https://doi.org/10.1029/2000JD900514

[12] Feng, Y., Ramanathan, V. and Kotamarthi, V. (2013) Brown Carbon: A Significant Atmospheric Absorber of Solar Radiation? Atmospheric Chemistry and Physics, 13, 8607-8621. https://doi.org/10.5194/acp-13-8607-2013

[13] Lin, G., Penner, J., Flanner, M., Sillman, S., Xu, L. and Zhou, C. (2013) Radiative Forcing of Organic Aerosol in the Atmosphere and on Snow: Effects of SOA and Brown Carbon. Journal of Geophysical Research: Atmospheres, 119, 7453-7476. https://doi.org/10.1002/2013JD021186

[14] Saleh, R., Marks, M., Heo, J., Adams, P., Donahue, N. and Robinson, A. (2015) Contribution of Brown Carbon and Lensing to the Direct Radiative Effect of Carbonaceous Aerosols from Biomass and Biofuel Burning Emissions. Journal of Geophysical Research: Atmosphere, 120, 10285-10296.

https://doi.org/10.1002/2015JD023697

[15] Shamjad, P.M., Tripathi, S., Pathak, R., Hallquist, M., Arola, A. and Bergin, M. (2015) Contribution of Brown Carbon to Direct Radiative Forcing over the Indo-Gangetic Plain. Environmental Science \& Technology, 49, 10474-10481. https://doi.org/10.1021/acs.est.5b03368

[16] Jo, D.S., Park, R., Lee, S., Kim, S. and Zhang, X. (2016) A Global Simulation of Brown Carbon: Implications for Photochemistry and Direct Radiative Effect. Atmospheric Chemistry and Physics, 16, 3413-3432. https://doi.org/10.5194/acp-16-3413-2016

[17] Hasan, M., Salam, A. and Alam, A. (2009) Identification and Characterization of Trace Metals in Black Solid Materials Deposited from Biomass Burning at the Cooking Stoves in Bangladesh. Biomass \& Bioenergy, 3, 1376-1380. https://doi.org/10.1016/j.biombioe.2009.05.023

[18] Sarkar, M.A.R. and Islam, S. (1998) Rural Energy and Its Utilization in Bangladesh. Energy, 23, 785-789. https://doi.org/10.1016/S0360-5442(98)00018-8

[19] Salam, A., Hasan, M., Begum, B., Begum, M. and Biswas, S. (2013) Chemical Characterization of Biomass Burning Deposits from Cooking Stoves in Bangladesh. Biomass \& Bioenergy, 52, 122-130. https://doi.org/10.1016/j.biombioe.2013.03.010

[20] Begum, B.A., Paul, S., Hossain, M., Biswas, S. and Hopke, P. (2009) Indoor Air Pollution from Particulate Matter Emissions in Different Households in Rural Areas of Bangladesh. Building Environment, 44, 898-903.

https://doi.org/10.1016/j.buildenv.2008.06.005

[21] Virkkula, A., Makela, T., Hillamo, R., Tuomi, T., Hirsikko, A., Hameri, K. and Koponen, I. (2007) A Simple Procedure for Correcting Loading Effects of Aethalometer Data. Air \& Waste Management Association, 57, 1214-1222. https://doi.org/10.3155/1047-3289.57.10.1214 
[22] Drinovec, L., Mocnik, G., Zotter, P., Prévôt, A., Ruckstuhl, C., Coz, E. and Rupakheti, M. (2015) The Dual-Spot Aethalometer an Improved Measurement of Aerosol Black Carbon with Real-Time Loading Compensation. Atmospheric Measurements Technique, 8, 1965-1979. https://doi.org/10.5194/amt-8-1965-2015

[23] Wang, Y., Hopke, P., Rattigan, O. and Zhu, V. (2011) Characterization of Ambient Black Carbon and Wood Burning Particles in Two Urban Areas. Environmental Monitoring, 13, 1919-1926. https://doi.org/10.1039/c1em10117j

[24] Haque, M.I., Nahar, K., Kabir, M.H. and Salam A. (2018) Particulate Black Carbon and Gaseous Emission from Brick Kilns in Greater Dhaka Region, Bangladesh. Air Quality Atmosphere and Health, 11, 925-935. https://doi.org/10.1007/s11869-018-0596-y

[25] Salam, A., Hasan, M., Begum, B.A., Begum, M. and Biswas, S.K. (2013) Chemical Characterization of Biomass Burning Deposits from Cooking Stoves in Bangladesh. Biomass and Bioenergy, 52, 122-130.

https://doi.org/10.1016/j.biombioe.2013.03.010 